\title{
Impact of Stray Voltage on Renewable Energy-based Farm in Pacific Island Country
}

\author{
F. R. Islam ${ }^{1}$, Ravneel Prasad ${ }^{2}$, Rezwanul Haque ${ }^{1}$, Vishal Sharma ${ }^{2}$ \\ ${ }^{1}$ School of Science and Engineering, University of the Sunshine Coast, Australia \\ ${ }^{2}$ Faculty of Science, Technology and Environment, University of the South Pacific (USP), Fiji
}

\begin{abstract}
Article Info
Article history:

Received Aug 21, 2019

Revised Oct 26, 2020

Accepted Nov 19, 2020

\section{Keywords:}

Stray voltage

Dairy farm

PV system

Renewable energy

PICs

ABSTRACT

Recent advancements in solar technology offer an enormous opportunity for the people of Pacific Islands to use electricity from the off-grid solar system for both their energy needs and farming activities. However, a farm's productivity and animal health might be seriously threatened if it experiences stray voltages caused by the improper grounding of its installed electrical systems. As a shift in the neutral point of an electrical system creates a current flow to the ground through conducting elements, the impacts of stray voltages need to be addressed from both technical and economic viewpoints. In this research, the effects of stray voltages passing through animals are explored using circuit designs for solar sources considering variable grounding resistances due to the different body resistances of various types of animals, and environmental and grounding design issues. A comparison of the stray voltages of two different sources (off-grid solar and traditional grid) with various configurations are conducted to determine their effects on a farm. Finally, their economic impacts together with possible techniques for mitigating them are explained.
\end{abstract}

Copyright $(2020$ Institute of Advanced Engineering and Science. All rights reserved.

\section{Corresponding Author:}

F. R. Islam,

School of Science and Engineerin,

University of the Sunshine Coast, Australia

Email: fislam@usc.edu.au

\section{INTRODUCTION}

Renewable energy (RE) will be the best choice for achieving sustainable development and ensuring a green, clean environment in the future. Due to their geographic locations, Pacific Islands are very suitable for implementing stand-alone RE sources, especially solar energy which has a lower installation cost than other sources, which will eliminate their dependence on imported fossil fuels for power generation. Solar systems are now becoming popular for farming activities in Fijian islands [1] despite their being associated with a few potential problems, such as stray voltages which need to be identified as they have huge impacts on the quality of a farmer's products and economic situation [2].

Tingling voltage, more formally known as a stray voltage, is relatively small voltage measured between two adjacent points of contact, results when current flows through a neutral conductor It is significant, especially for cattle farms as even a low voltage could have an impact on livestock. The U.S. Department of Agriculture defines a stray voltage as being as small as less than $10 \mathrm{~V}$ that can be measured between two conceivable contacts [3]. The two major contributors to stray voltages are: an unbalanced electrical load (excessive neutral current) of households, industries, and entrepreneurs which leads to a rise in the neutral-toearth voltage (NEV); and the primary neutral voltage resulting from poor grounding [4].

Stray voltages raise health concerns for animals due to their low body resistance [5], as they result in changes in animals' behavioral patterns that cause reductions in their milk and meat production which, in particular, pose great risks to the financial structures of the dairy and meat industries. The effect on cattle 
directly exposed to an electrical current vary from minor behavioral reactions symptomatic of sensations to unintentional muscle contractions to intense responses indicating pain while indirect exposure depends on the point of contact, level of current flow, body pathway and frequency of occurrence which may have similar consequences but on a smaller scale [2]. Table 1 shows the impacts of different stray currents on livestock. Although a few counter-measures have been proposed and enforced to alter farming practices regarding stray voltages, especially in developed countries, this scenario is quite different in developing countries such as Fiji, a Pacific Island Country (PIC). Traditionally, most Fijian village families have their own small dairy farm, with the majority of their farming practices not monitored and farmers unaware of stray voltages which are related to a soil's fertility, presence of NEV and other factors [6].

Table 1. Impact of stray currents on livestock [2]

\begin{tabular}{|c|c|c|}
\hline Current[mA & & Behavioral Response \\
\hline $\begin{array}{l}1- \\
3\end{array}$ & - $\quad$ Basic Awareness & $\begin{array}{l}\text { Animals, especially cows, sheep, chickens and pigs, } \\
\text { indicate the presence of a tingling voltage by lifting their } \\
\text { legs, flinching, blinking their eyes, shifting their weight or } \\
\text { performing certain actions they have been trained to do in } \\
\text { response to an inducement. }\end{array}$ \\
\hline $\begin{array}{l}4- \\
6\end{array}$ & - $\quad$ Behavioural Response & $\begin{array}{l}\text { These involve actions such as flinching or delaying } \\
\text { drinking water. }\end{array}$ \\
\hline Current $>6$ & - $\quad$ Production Loss & $\begin{array}{l}\text { Over a continuous period, animals' intakes of water and } \\
\text { feed are reduced, resulting in lower meat and milk } \\
\text { production. }\end{array}$ \\
\hline
\end{tabular}

The climate of a PIC is tropical in nature [7]. Due to the geographic location [8], energy generation and distribution expenses in an Island [9] and overall economic situation [10], people relying heavily on RE resources (solar energy) for daily supplies of electricity. Unfortunately, using solar energy on a farm has a few disadvantages, as experienced in various parts of the world [11].

To ensure maximum safety given unintended fault currents or lightning surges, an electrical grounding system should have a low impedance path. Prior to its installation, variables such as its worst-case fault conditions, grounding paths, size, design, and placement as well as the resistivity of the soil need to be considered. A low grounding impedance path can be ensured through proper design of the resistance of the grounding electrodes and the depth to which the element is driven based on the soil's resistivity, as categorized by the amounts of moisture, and mineral and dissolved salt contents in it. Moisture influences a soil's resistivity in carrying electrical currents and, if it decreases to less than ten percent, the soil's resistivity increases significantly [12].

This paper discusses the effects of stray voltages on different types of livestock on a farm. It also compares the stray voltage of a grid-connected farm with an islanded solar energy system-based one with different grounding configurations in a software environment considering the impacts of lightning and deterioration of their grounding systems over time. Various studies indicate that stray voltages and currents greatly influence the behaviors of livestock on a farm, as clearly shown by [2] (Table 1).

\section{EXPERIMENTAL FARM}

Fiji is a tropical island situated in the South Pacific Ocean on the southern boundary of the tropics [13]. Thus, Fiji is very suitable for stand-alone RE sources, particularly solar PV systems. Most of its islands are not connected to the national power grid and some have no electricity at all [1]. Therefore, to meet the essential demand for electricity on a dairy farm, interest in solar PV systems is continually increasing.

Although the proper installation and grounding of RE sources are very important to avoid stray voltages, people sometimes tend to ignore grounding issues [14]. To identify the level of stray voltages in a PV system, the test farm designed for this research is based on data collected from a real Fijian Kandavu Island dairy farm, as shown in Table 2.

Table 2. Livestock and facilities of the experimental farm

\begin{tabular}{ccc}
\hline Facility & Number of Livestock & Size (m2) \\
\hline Milking parlour & 50 & 500 \\
Goat shed & 50 & 400 \\
Poultry house & 100 & 200 \\
\hline
\end{tabular}

IJEEI, Vol.8, No. 4, December 2020: 795 - 805 
Its loads are connected in different phases of a three-phase solar system, as shown in Figure 1.

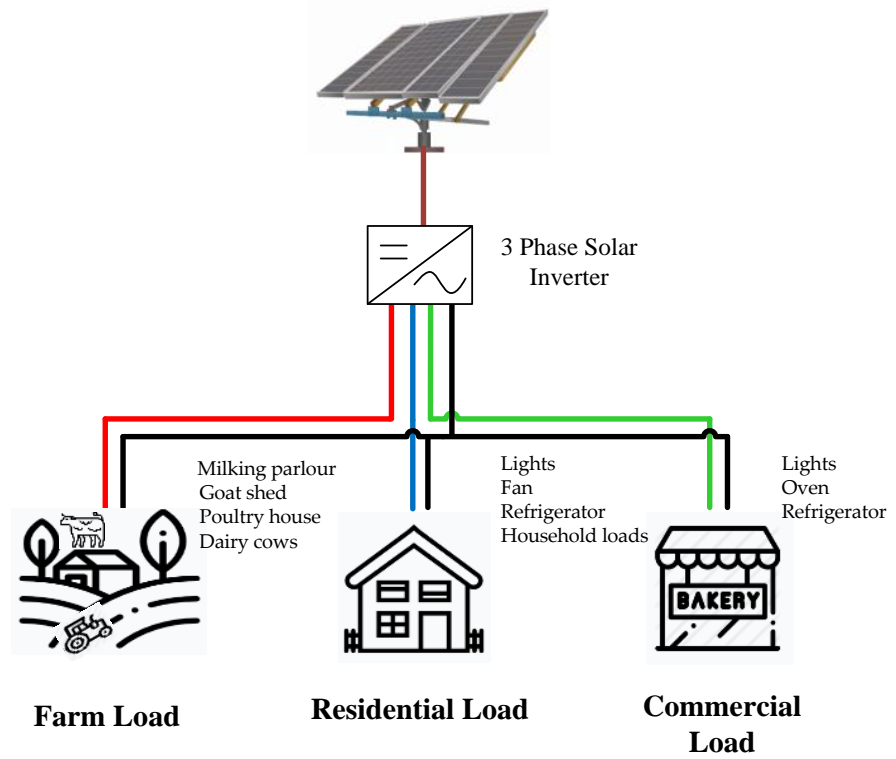

Figure 1. Three-phase electrical network of solar-based farm.

The number of, and required space for, each type of livestock are given in Table 2 and the electrical loads in Table 3

Table 3. Electrical loads of test farm.

\begin{tabular}{|c|c|c|c|c|}
\hline Faculty & Load & Power $(\mathrm{W})$ & Usage (h/day) & Energy (Wh/day) \\
\hline \multirow{6}{*}{ Poultry House } & Lighting (12 x 12W LED Bulbs) & 144 & 23 & 3312 \\
\hline & Fans $(3 \times 750 W)$ & 2250 & 6 & 13500 \\
\hline & Heating Equipment $(2 \times 100 \mathrm{~W})$ & 200 & 6 & 1200 \\
\hline & Heating Equipment $(2 \times 100 \mathrm{~W})$ & 200 & 6 & 1200 \\
\hline & Water Pump & 171.5 & 4 & 686 \\
\hline & Total & 2965.5 & & 19898 \\
\hline \multirow{5}{*}{ Goat Shed } & Inner Lighting (16 x 18W) & 288 & 3 & 864 \\
\hline & Outer Lighting ( 2 x 18W) & 36 & 10 & 360 \\
\hline & Heating Equipment (4 x 100W) & 400 & 6 & 2400 \\
\hline & Water Pump & 171.5 & 4 & 686 \\
\hline & Total & 895.5 & & 4310 \\
\hline \multirow{8}{*}{$\begin{array}{l}\text { Milking } \\
\text { Parlour }\end{array}$} & Inner Lighting (16 x 18W) & 288 & 3 & 864 \\
\hline & Outer Lighting ( 2 x 18W) & 36 & 10 & 360 \\
\hline & Milking machine & 900 & 2 & 1800 \\
\hline & Chilling Machine & 60000 & 2 & 120000 \\
\hline & Fans $(3 \times 750 W)$ & 2250 & 2 & 4500 \\
\hline & Water Pump & 171.5 & 3 & 514.5 \\
\hline & Freezers $(3 \times 120 W)$ & 360 & 24 & 8640 \\
\hline & Total & 64005.5 & & 136678.5 \\
\hline TOTAL & Total Demand & 67866.5 & & 160886.5 \\
\hline
\end{tabular}

Apart from the farm load, the other two phases incorporate the residential and commercial loads shown in Table 4 [1] and Table 5 respectively. The former comprises the typically small amounts of power consumed by households and the latter those of the shops, office and other buildings in the area.

Table 4. Residential loads.

\begin{tabular}{cccc}
\hline Load & Power $(\mathrm{W})$ & Usage (hrs/day) & Energy (Wh/day) \\
\hline Light & 9 & $1-6$ & $9-54$ \\
Water pump/iron/water heater & 400 & $2-3$ & $800-1200$ \\
Mobile phone & 10 & 3 & 30 \\
Radio & 40 & $1-14$ & $40-560$ \\
Computer & 250 & $2-6$ & $500-1500$ \\
TV & 65 & 3 & 195 \\
Fridge & 185 & 4 & 740 \\
Fan & 40 & $1-6$ & $40-240$ \\
\hline
\end{tabular}


Table 5. Commercial loads.

\begin{tabular}{cccc}
\hline Load & Power $($ W $)$ & Usage( hrs/day) & Energy $($ Wh/day) \\
\hline Lights & 65 & $1-6$ & $65-390$ \\
Water pump/water heater & 800 & $2-3$ & $1600-1800$ \\
Electronic gadgets & 650 & $6-12$ & $3900-7800$ \\
Fridge & 185 & $9-12$ & $1665-2220$ \\
Fan & 120 & $3-8$ & $360-960$ \\
Air conditioning & 1000 & $5-12$ & $5000-12000$ \\
\hline
\end{tabular}

\section{DESIGN OF ELECTRICAL SYSTEM}

A solar system is designed for the experimental farm to compare the stray voltage levels obtained from a solar energy source and grid-connected electric network with various grounding configurations. A threephase delta-connected grid source with a voltage rating of $415 \mathrm{~V}$ is considered for the farm, with the connection converted to a wye connection using a transformer to step down the voltage for devices. To provide the same amount of energy from the solar PV system with AC output as that from the grid, the three essential components are the solar panel, DC-DC boost converter, and inverter. A solar system is designed based on [15] and [16] using the parameters given in Table 6 .

Table 6. Solar panel specification.

Cells in series: 36, parallel: 10
Modules in series: 15 , parallel: 25
Boost converter: inductance $=100 \mu \mathrm{H}$, capacitance $=1000 \mu \mathrm{F}$
DC link capacitance: $1000 \mu \mathrm{F}$

A six-pulse bridge rectifier is used to convert the DC voltage to AC and PI controllers to control the DC voltage and reactive power. The DC voltage controller uses two regulating circuits, DC voltage and quadrature current (Iq) regulators, while the reactive power controller uses the reactive power and direct current regulators. The inverter control circuits and the configuration of the control system are shown in Figure 2 and Figure 3 respectively.

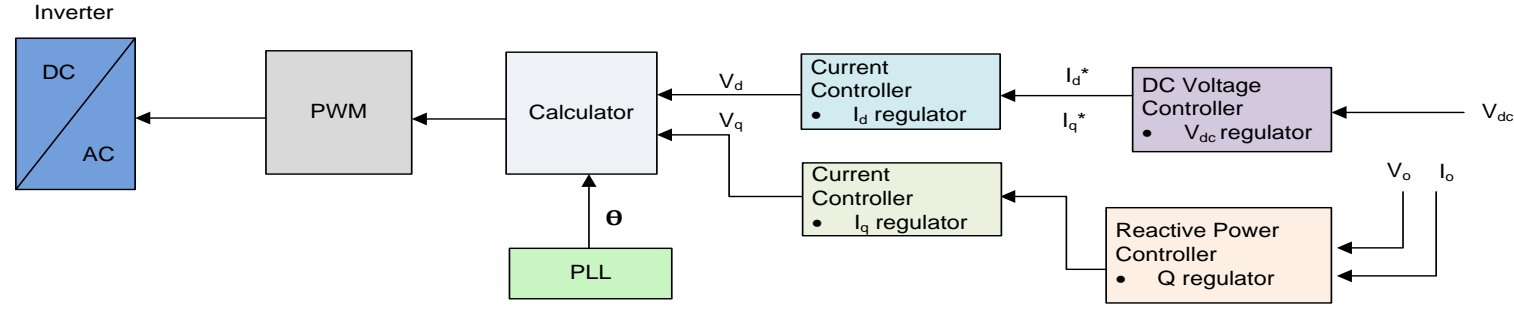

Figure 2. Inverter system.
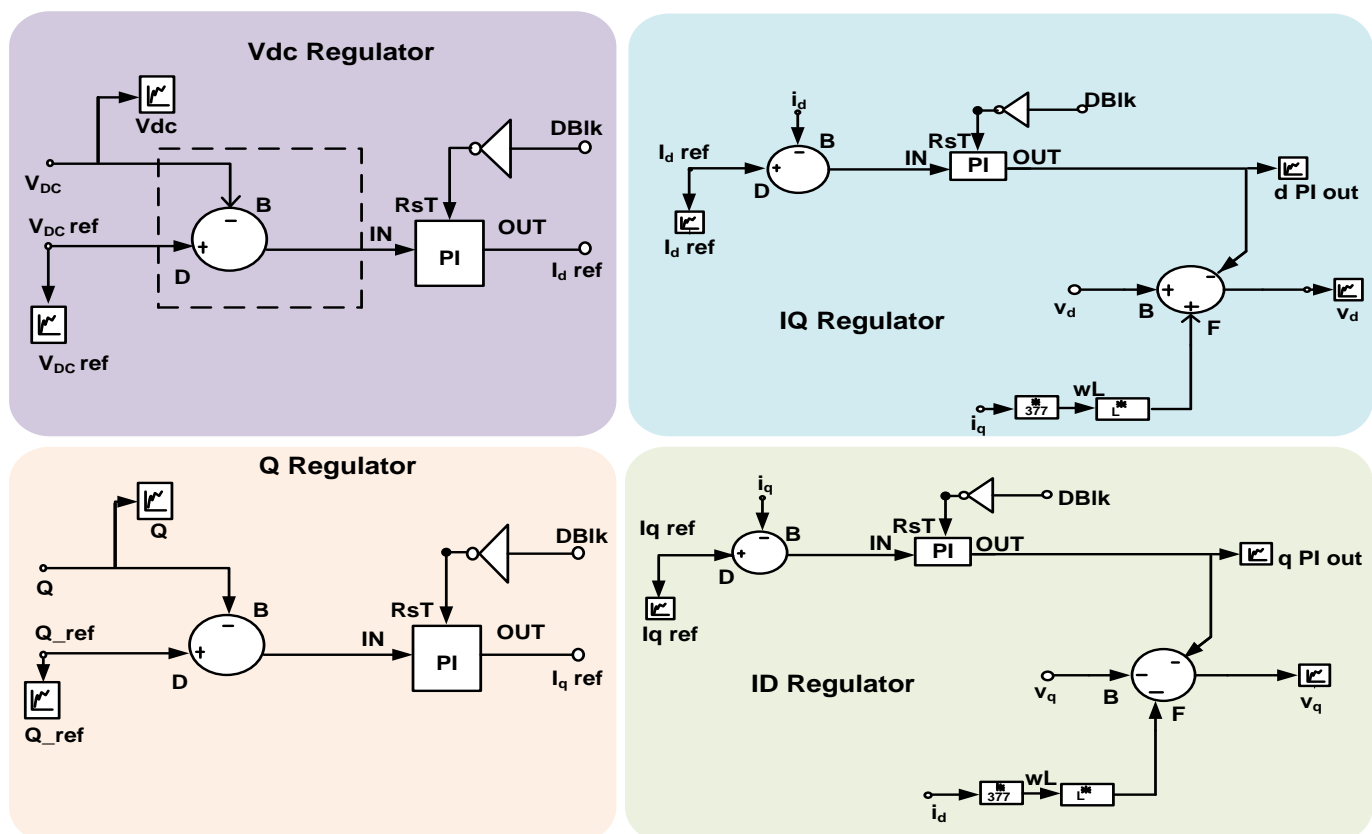

Figure 3. Configuration of the control system for solar energy generation. 
As the overall load of the system is distributed through three feeders, it is expected that the system will be unbalanced due to the variable load demand. Considering this situation, each feeder's load consists of resistance and inductance in a series in each phase, where the inductance values are the same for all three phases at $0.01 \mathrm{H}$ and the resistance ones set to $60 \Omega, 80 \Omega$ and $90 \Omega$ respectively, as seen in Figure 4 .

The farm load is connected through a three-phase centre tap transformer to the residential and commercial loads. For the initial experiment, three tap grounding rods connected through a resistance of $0.2 \Omega$ are considered in parallel, with the farm load connected to the second and third windings of the transformer, where windings 2 and 3 have series resistances of $0.002 \Omega, 2 \Omega$, and $31.75 \Omega, 0.002 \Omega$ respectively. Both windings are connected with a resistance of $0.002 \Omega$ parallel to the windings. All the connections in the network are shown in Figure 4, where those of the farm and transformer are grounded using a 'trough rod'.

The animal's resistance is connected in parallel to the customer load, with the trough grounding indicating that the animal comes in contact with the stray voltage.

There are multiple factors that affect the grounding resistance and determine the level of the NEV. A lower resistance between the neutral point of the circuit and the earth (or ground) allows any excess electrical current to flow directly to the ground without causing an offset in the neutral point. If this resistance increases, the voltage between the two points also increases following Ohm's law and causes a higher stray voltage.

Due to the continuous deterioration of the electrical grounding rod due to various natural activities and chemical reactions, and the presence of mineral and soil characteristics, its resistance increases and leads to the NEV over time. It is understood that the resistivity of an electrical rod depends greatly on its crosssectional area as they are inversely proportional, thereby indicating that a reduction in its cross-sectional area would increase the resistance of the grounding rod.

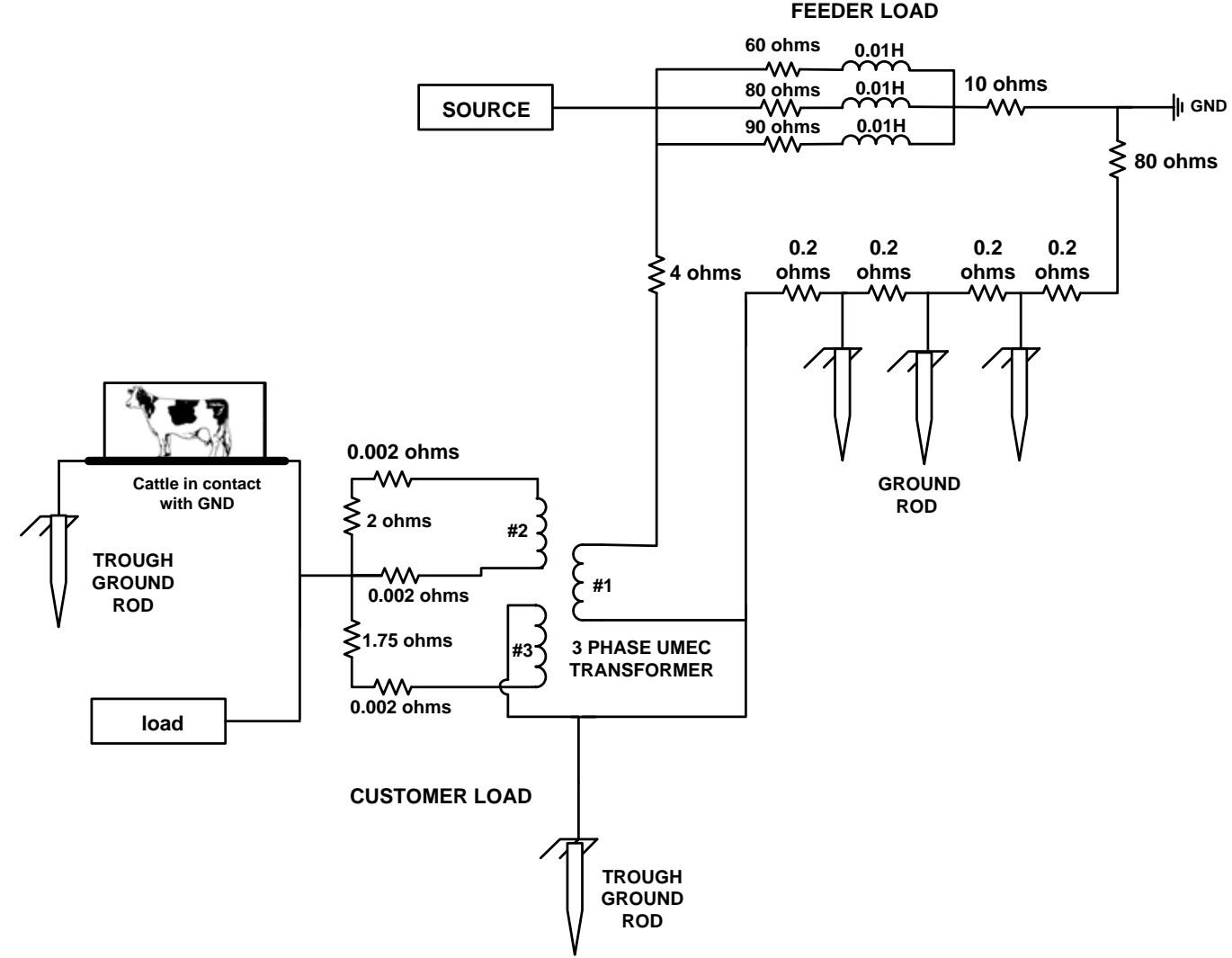

Figure 4. Network configuration.

Another factor is the weather which causes a change in the ground's chemical composition. As Fiji is a tropical country, its weather is a mixture of long periods of sunshine and rainy or stormy seasons. The western part of the country usually experiences drought as it receives very little rain over a year unless, or until, a hurricane occurs. The soil in this part of the country is relatively dry and, at times, like sand with very little moisture content which results in its grounding resistance being high as its structure has very few or no mobile electron particles (due mainly to its lack of moisture and minerals). On the other hand, during its stormy or hurricane season, the country receives a large amount of rain which sometimes causes flooding in most areas. During this period, as most of the soil's nutrients are washed away, there is a decrease in its mobile electrons which tends to increase its resistance. This phenomenon of the washing away of nutrients is understood by 
studying a river diverted onto a new path where the soil is rich in nutrients (e.g., loam soil). A long period of constant water movement in this new path will cause gravel or sand to be formed as a layer in the bed of the river because the soil's nutrients and other components are washed away. A sandy or gravelly soil has more resistance than a loam one [18]. The typical levels of resistivity of different soils varies from $1 \Omega$ to $10000 \Omega$ $[17,18]$.

Also, due to the lightning and thunderstorms experienced by Fiji during the cyclone season, the structure of the soil changes to a more fulgurite crystalline form [19] which is known to have high electrical resistance. Other external factors contributing to NEV could be:

- $\quad$ faulty, failing or undersized wiring, panels, services or transformers;

- $\quad$ improper wiring, bonding, grounding or current flows;

- $\quad$ current leakages;

- $\quad$ improper use of neutral and grounding conductors;

- $\quad$ failure or deterioration of equipment and appliances;

- corrosion of connections; and/or

- $\quad$ poor or old connections.

To identify the impact of a stray voltage on a farm, it is important to understand the electrical connection of the farm. To model a system for a single farm, it is necessary to represent the grounding and neutral conditions as well as the unbalancing of the load in a customer's facility [20]. Figure 5 illustrates the modelled farm with two energised conductors (A and B), either of which can be used with a neutral connection. It is also clear that the customer load can be connected to the ground from this neutral connection at only one location although the overall design is the Multi-grounded Neutral (MGN) network shown in Figures 4 and 5.

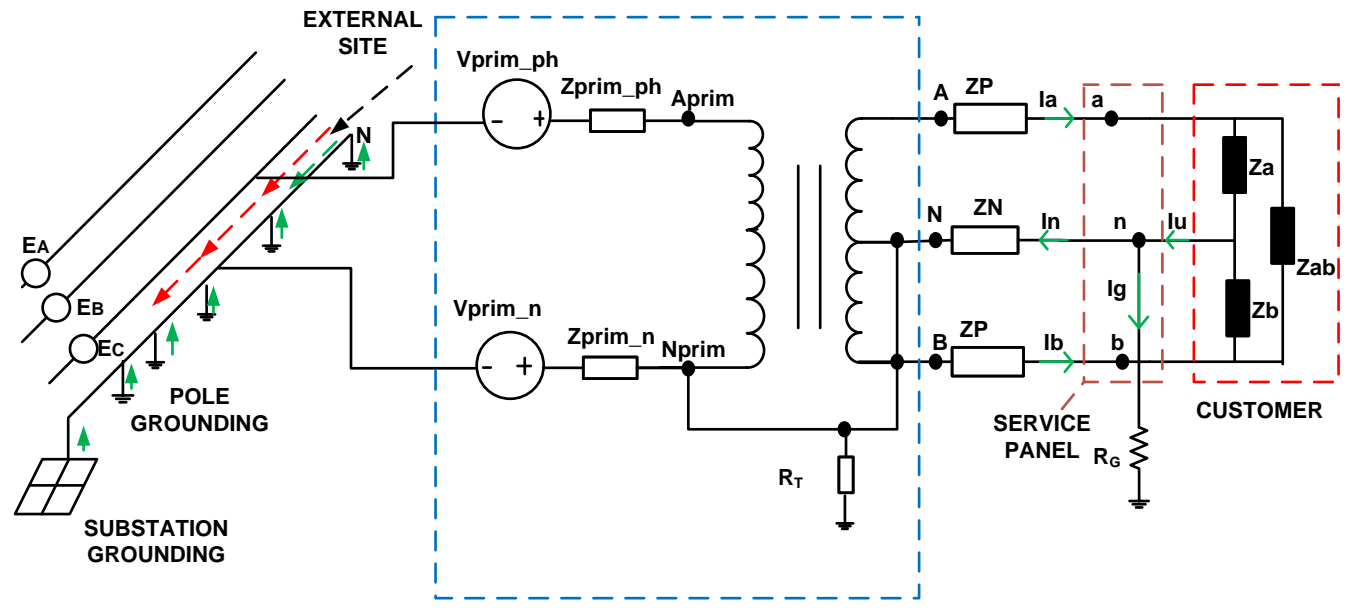

Figure 5. Illustration of the farm's electrical network.

The load of the single farm is connected through a 3-winding, single-phase transformer, with their groundings represented as RG and RT respectively. Based on the electrical network in Figure 5, a stray voltage (Vn) or NEV can be expressed as:

$$
N E V=V n=R_{G} \times I_{g}=R_{G} \times\left(I_{u}-I_{n}\right)
$$

The current due to the unbalanced load is given by IU which indicates the presence of NEV in the system. The other contributors to a NEV are external factors such as improper grounding and an unbalanced feeder load in a distribution network.

$\mathrm{V}_{\text {Prim_n }}$ is the NEV on the primary side of the transformer generated by external factors in the network which indicates that the voltage is due to an unbalanced distribution load or faults in the distribution network flows through the neutral point connection to the customer side which causes the NEV to increase and flow through the ground.

The current flow in the neutral point $\left(I_{n}\right)$, the current generated through external factors (Ine) and unbalanced load can be related by the ratio:

$$
K=\frac{I_{n}+I_{n e}}{I_{u}}
$$

From this equation, it can be determined that the value of $K$ would be less than 1 if there is a flow of current to the ground which would indicate the presence of a stray voltage when anything with an impedance comes into contact with such a current. 
In order to determine the value of $\mathrm{K}$, the customer load in Figure 5 must be transformed from a delta to wye connection.

The total impedance of the multiple neutral groundings on the primary side parallel with RT is represented by ZMGN and the neutral-point voltage on the primary side by VMGN. The customer loads are supplied through impedances of zp and $\mathrm{zn}$, as can be seen in Figure 6 (A), and the network can be further simplified by using the Thevenin's equivalent of the circuit shown in Figure 6 (B).

$$
\begin{gathered}
V_{t h}=\frac{\left(z_{p}+Z_{2}\right) V_{a}-\left(z_{p}+Z_{1}\right) V_{b}}{\left(z_{p}+Z_{2}\right)+\left(z_{p}+Z_{1}\right)} \\
Z_{t h}=\frac{\left(z_{p}+Z_{1}\right)\left(z_{p}+Z_{2}\right)}{\left(z_{p}+Z_{2}\right)+\left(z_{p}+Z_{1}\right)}+Z_{3} \\
V_{M G N}-Z_{M G N} I_{g}+z_{n} I_{n}-R_{G} I_{g}=0
\end{gathered}
$$

(A)

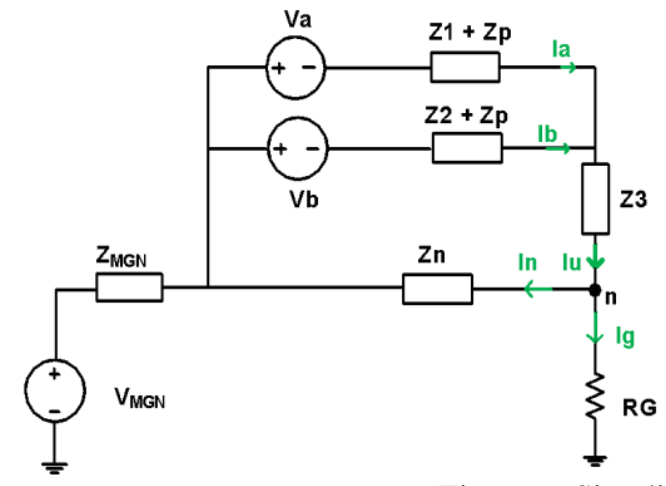

Figure 6. Simplified circuit for analysis.

(B)

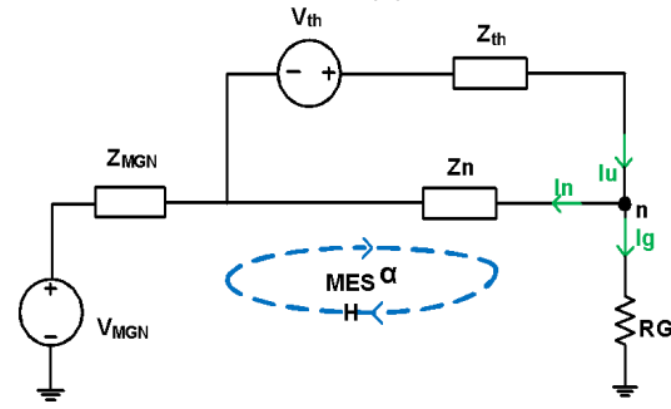
equation (7):

By rearranging equation (4) and replacing the grounding current $(\mathrm{Ig})$ by its equivalence $(\mathrm{Iu}-\mathrm{In})$ in

$$
I_{n}=K \times I_{u}-I_{n e}
$$

In Figure 5, it can be seen that the unbalanced load current ( $\mathrm{Iu}$ ), neutral line current (In) and grounding current (Ig) are related as:

$$
I_{g}=I_{u}-I_{n}
$$

Substituting equation (9) into equation (7):

$$
\begin{gathered}
V_{M G N}-Z_{M G N}\left(I_{u}-I_{n}\right)+z_{n} I_{n}-R_{G}\left(I_{u}-I_{n}\right)=0 \\
V_{M G N}-\left(Z_{M G N}+R_{G}\right)\left(I_{u}-I_{n}\right)+z_{n} I_{n}=0
\end{gathered}
$$

Then, by rearranging equation (10):

$$
I_{n}=\frac{Z_{M G N}+R_{G}}{Z_{M G N}+R_{G}+z_{n}} I_{u}-\frac{V_{M G N}}{Z_{M G N}+R_{G}+z_{n}}
$$

Equations (8) and (12) can be compared to determine the equation for K through which the current's return ratio can be established.

$$
K=\frac{Z_{M G N}+R_{G}}{Z_{M G N}+R_{G}+z_{n}}
$$

Equation (13) indicates that an increase in the neutral impedance would affect the value of the stray voltage induced and a decrease in $\mathrm{K}$ an increase in the stray voltage in the system.

\section{SIMULATION FOR IDENTIFYING THE IMPACT OF STAY VOLTAGE}

To understand the effect of stray voltages in a farm, two different sources (an off-grid PV system and utility grid) for feeding the customer load and associated feeders are considered separately. Due to the fact that the resistance of the grounding rod could be changed, in this study, values from $0 \Omega$ to $600 \Omega$ are used. As the unbalanced loads of the feeder have a significant impact on the introduction of a NEV and consequently the stray voltage, this research compares two different scenarios: 1) an unbalanced grid-connected feeder; and 2) an unbalanced PV-connected feeder. Figure 7, shows the NEV under three different conditions: all the ground 
rods are working in the system, all feeder rods are removed and then all the customer rods are removed while the other sets of rods are in working state in test farm. It has been observed that the impact of customer rods removal is higher than the feeder rods.
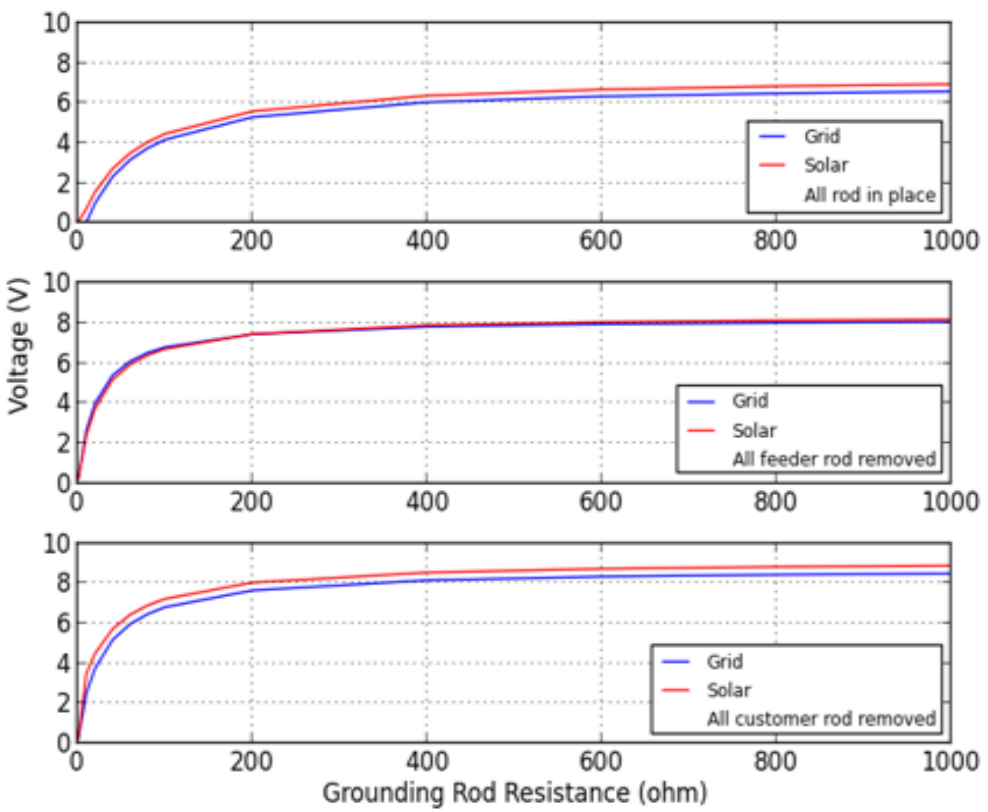

Figure 7. NEV for different grounding configurations at the network with variable resistances.

To understand the consequences of removing the customer loads trough rod and the transformer trough rod two different test have been conducted through removing those rods. Figure 8, shows the NEV when the trough rod of customer load and transformer has been removed. It has been found that the impact of stray voltage is higher with the removal of customer load trough rod.

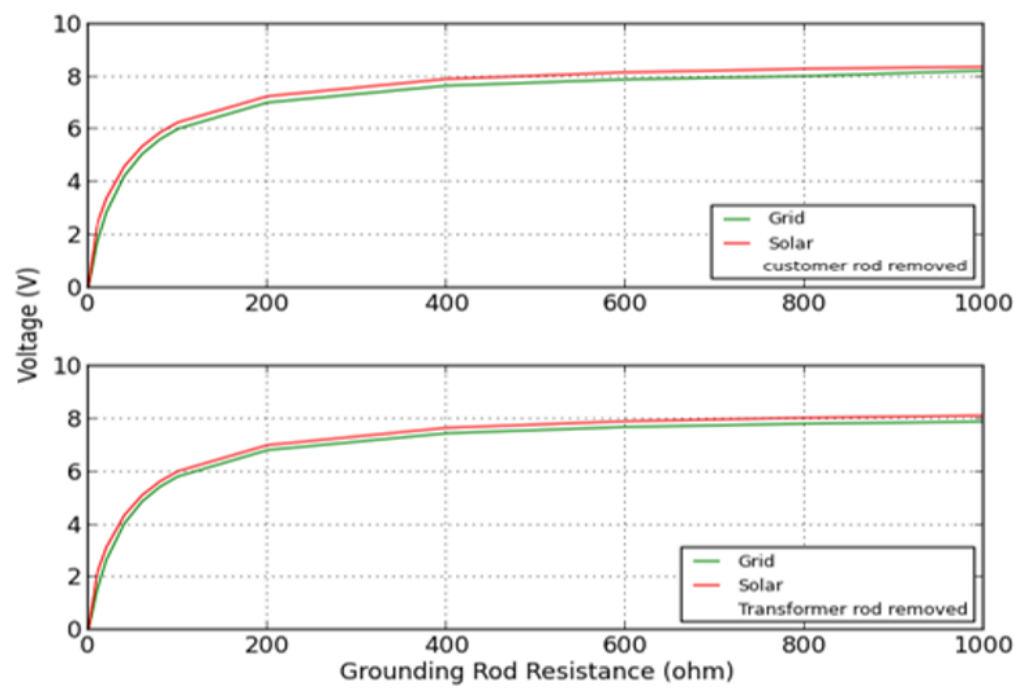

Figure 8 . NEV for different grounding configurations at the customer side with variable resistances.

In order to better understand the performance of a grounding rod for protecting against a stray voltage, its resistance is increased and it is found that the system experiences a higher stray voltage. In this designed farm, 5 grounding rods are used, three for the feeder and two for the customer side to protect the NEV. Their impacts are identified by using different combinations of them in various simulations by removing them consequently. The results provide a clear picture of the impacts of stray voltages using these configurations. This experiment indicates that the poor or improper grounding of a solar PV system in a farm causes a higher

IJEEI, Vol.8, No. 4, December 2020: 795 - 805 
stray voltage, this is also evident for a goat farm with balanced and unbalanced feeder loads and various active configurations of grounding rods as shown in Table 7. Also, it is found that, with an increase in grounding resistance, stray voltages through animals increase which, eventually, decreases the economic output of the farm. This is explained in the next section because it has been observed that the number of solar-based farms in PICs has been increasing recently.

Table 7. NEV outputs with various grounding resistances.

\begin{tabular}{|c|c|c|c|c|c|c|c|c|c|}
\hline \multicolumn{10}{|c|}{ Stray/Tingle Voltage (Goat/Sheep with $200 \Omega$ resistance) } \\
\hline \multirow[b]{2}{*}{ 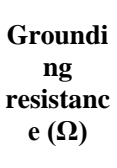 } & \multicolumn{3}{|c|}{ All 5 Grounding Rods Active } & \multicolumn{3}{|c|}{ Only Customer Rods Active } & \multicolumn{3}{|c|}{ Only Feeder Rods Active } \\
\hline & $\begin{array}{c}\text { Grid } \\
\text { source } \\
\text { unbalanc } \\
\text { ed }(\mathbf{V})\end{array}$ & $\begin{array}{c}\text { PV } \\
\text { source } \\
\text { unbalanc } \\
\text { ed }(V)\end{array}$ & $\begin{array}{c}\text { PV } \\
\text { source } \\
\text { balanc } \\
\text { ed }(V)\end{array}$ & $\begin{array}{c}\text { Grid } \\
\text { source } \\
\text { unbalanc } \\
\text { ed }(V)\end{array}$ & $\begin{array}{c}\text { PV } \\
\text { source } \\
\text { unbalanc } \\
\text { ed }(V)\end{array}$ & $\begin{array}{c}\text { PV } \\
\text { source } \\
\text { balanc } \\
\text { ed }(V)\end{array}$ & $\begin{array}{c}\text { Grid } \\
\text { source } \\
\text { unbalanc } \\
\text { ed }(\mathbf{V})\end{array}$ & $\begin{array}{c}\text { PV } \\
\text { source } \\
\text { unbalanc } \\
\text { ed }(\mathbf{V})\end{array}$ & $\begin{array}{c}\text { PV } \\
\text { source } \\
\text { balanc } \\
\text { ed }(V)\end{array}$ \\
\hline 10 & 1.271 & 1.709 & 1.564 & 2.617 & 2.376 & 2.175 & 1.991 & 2.707 & 2.478 \\
\hline 20 & 2.234 & 2.532 & 2.318 & 3.943 & 3.672 & 3.361 & 3.203 & 3.693 & 3.380 \\
\hline 40 & 3.519 & 3.664 & 3.354 & 5.28 & 5.05 & 4.622 & 4.582 & 4.869 & 4.457 \\
\hline 60 & 4.335 & 4.412 & 4.039 & 5.952 & 5.772 & 5.284 & 5.344 & 5.548 & 5.079 \\
\hline 80 & 4.899 & 4.943 & 4.525 & 6.357 & 6.217 & 5.691 & 5.827 & 5.991 & 5.484 \\
\hline 100 & 5.312 & 5.34 & 4.888 & 6.627 & 6.518 & 5.967 & 6.160 & 6.302 & 5.768 \\
\hline 200 & 6.383 & 6.403 & 5.861 & 7.242 & 7.218 & 6.607 & 6.955 & 7.062 & 6.464 \\
\hline 400 & 7.095 & 7.137 & 6.533 & 7.594 & 7.627 & 6.982 & 7.433 & 7.533 & 6.895 \\
\hline 600 & 7.368 & 7.425 & 6.797 & 7.719 & 7.774 & 7.116 & 7.608 & 7.707 & 7.055 \\
\hline 800 & 7.513 & 7.579 & 6.938 & 7.783 & 7.85 & 7.186 & 7.698 & 7.798 & 7.138 \\
\hline 1000 & 7.602 & 7.675 & 7.025 & 7.822 & 7.896 & 7.228 & 7.753 & 7.854 & 7.189 \\
\hline
\end{tabular}

\section{ECONOMIC ANALYSIS}

Over the years, various studies have been conducted on the effects of stray voltages on business infrastructures, especially those of cattle farms [5], as they can impact on a farm's economy which is highly dependent on the quality of its milk [21]. The existence of stray voltages over a continuous period can cause behavioural changes in animals, including their eating and drinking habits [21].

When animals are exposed to stray voltages while eating or drinking, production levels can decline which increases production costs. Also, due to interruptions of the milking process, as management faces production delays, additional time and money need to be invested in the production process [2],[22]. The impact of stray voltages on the farm on a Fijian island and the experimental solar energy-based one are illustrated in order to better understand the economic losses incurred.

According to FAOSTAT [23], Fiji Island has a good history of cattle farming, with its total numbers of cattle (cows) increasing every year, from approximately 28,000 in the year 2000 to around 31,000 in the year 2016 in which the average milk production per cow was 1787 litres. The presence of stray voltages in a farm can reduce the quantity of milk per cow by 0.16 litres/day [3], an estimated reduction of $3.26 \%$ in total milk production. Figure 9, shows the milk production levels in Fiji from the years 2000 to 2016 which indicates a decreasing trend from 2012 and further reduction of milk production is predicted using exponential smoothing (ETS) method caused by the impact of stray voltages.

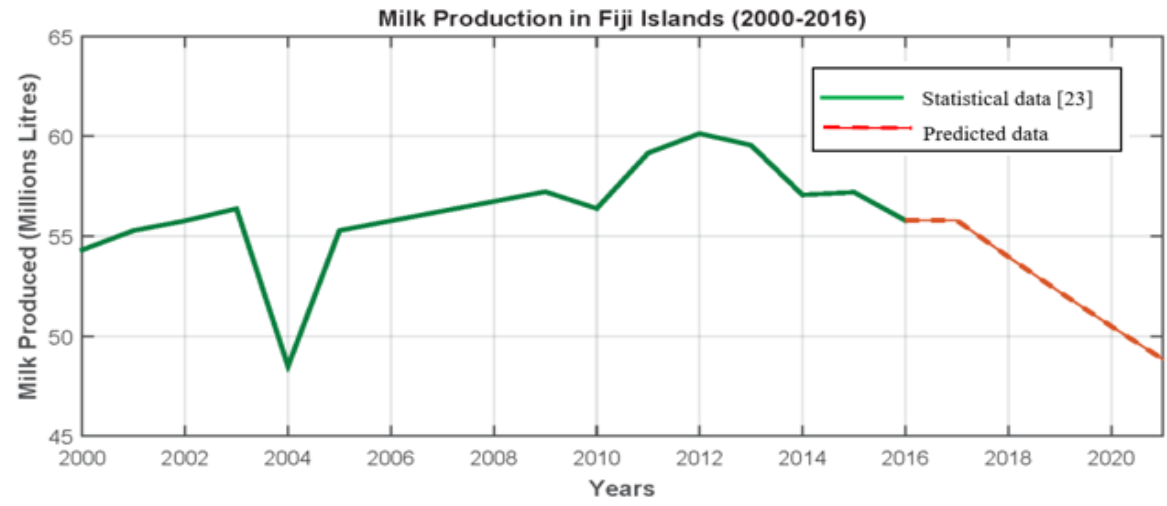

Figure 9. Levels of milk production in Fiji and forecasts considering the presence of stray voltage.

Considering the likelihood that cows are milked once a day, the total annual loss would be 2920 litres. As 1 litre of cow milk has recently been valued at \$0.78 FJD [24], the monetary values of total milk production and loss would be \$75621 FJD and \$2277.60 FJD respectively, with the overall total loss estimated to be 3\% 
and that of a loss from goat milk almost the same. These are considerable losses taking into account the social and economic conditions of a PIC.

\section{DISCUSSION AND POSSIBLE SOLUTION}

Cattle are considered to be more vulnerable to stray voltages/currents than humans because they have less bodily resistance. A voltage does not pose a problem for cows unless they come into contact with it and, even then, its source, path, contact, and bodily impedances have to be such that it will result in a current that will affect them. Although a stray voltage was previously considered to be one up to $10 \mathrm{~V}$ [3], based on recent research, cattle should not come in contact with voltages from low-impedance sources greater than $4 \mathrm{~V}$ [25].

Mitigating existing problems and preventing future ones need careful consideration of electrical sources, animal sensitivities and the characteristics of corrective procedures. Also, the effects of any modifications to an electrical system on either a farm or in a power distribution network under normal or fault conditions must be taken into account.

Approaches for controlling stray voltages or NEVs fall into the following four categories.

- Voltage Reduction through mitigating causative or exacerbating conditions (e.g., by removing bad neutral connections and faulty loads, improving or correcting wiring and grounds, balancing loads and/or controlling the leakage of currents by cleaning, reinsulating and/or grounding) [26].

- $\quad$ Active Suppression of the voltage using a nulling device [27].

- Gradient Control using equipotential planes and transition zones to maintain animals' step and touch potentials at an acceptable level [28].

- Isolation of a portion of the grounding or grounded neutral system from animals [29].

These four techniques are accessible for managing stray voltage. Since most on-homestead occurrences of them can be satisfactorily managed by changing the wiring, balancing the load, adjusting the grounding (such as replacing the grounding rods), diminishing spillage and rectifying faults (reducing the voltage), the majority of work has been focused on techniques for managing off-farm sources. The most widely recognized off-homestead source is the intrinsic impedance of the grounded-neutral arrangement of the primary energy source. However as, generally, it won't be functional to reduce the resistance of the grounding of the primary or impedance of the neutral source to the point of solving issues of increases in voltages for domesticated animals, different measures for shielding them from stray voltages/currents are being investigated. Therefore, the on-homestead procedures mentioned above (voltage reduction, active voltage suppression, gradient control and isolation) are choices which can be considered. Additional work is expected to help electricity suppliers create and select proper methodologies for addressing the issues in particular situations. Also, there are circumstances in which electrical issues on adjoining farms or residences can influence the NEV of a distribution primary on a farm, such as the normal interconnection of secondary neutral to primary neutral sources at each farm or residence. Identifying and mitigating these issues in different areas may take care of any non-partisan to-earth issue on a farm.

\section{CONCLUSION}

A stray voltage can decrease the quantity and quantity of goods produced on a farm. To investigate its technical and economic impacts on the production of a solar energy-based dairy farm on an island, this research study designed an experimental farm and conducted a simulation. It was found that, with proper grounding, the level of a stray voltage could be kept as low as $0.17 \mathrm{~V}$ while poor grounding could increase it up to $8 \mathrm{~V}$ which could be very dangerous for the health of animals as well as disadvantageous for the farm's overall production. Although not sufficient to kill or render any species of livestock unconscious, it could cause them to avoid the source of a stray voltage.

This research considered that an island dairy farm would use solar energy as its power source due to the likelihood of there not being a utility grid in that location. Therefore, comparisons of solar and utility gridbased systems with both balanced and unbalanced loads were conducted. As the investigation showed that the unbalanced solar-based network had the highest possibility of having a stray voltage, this issue needs to be seriously considered when dealing with solar or any other source of renewable energy in terms of the development of farms and farmers' long-term economic losses in PICs.

\section{REFERENCES}

[1] F. R. Islam, \& Mamun, K. A. (2017). Possibilities and Challenges of Implementing Renewable Energy in the Light of PESTLE \& SWOT Analyses for Island Countries. In Smart Energy Grid Design for Island Countries,1-19. Springer, Cham.

[2] Gustafson, R. J., Brennan, T. M., \& Appleman, R. D. (1985). Behavioral studies of dairy cow sensitivity to AC and DC electric currents. Transactions of the ASAE, 28(5), 1680-1685 
[3] Lefcourt, A. M. (1991). Effects of electrical voltage/current on farm animals: How to detect and remedy problems. United States Dept. of Agriculture, Agriculture Research Service.

[4] Reinemann, D. J., \& Board, O. E. (2008). Literature review and synthesis of research findings on the impact of stray voltage on farm operations. Ontario Energy Board.

[5] Reinemann, D. J. (2009). What do we know about Stray Voltage? Madison, University of Wosconsin, 12.

[6] Fiji National Agricultural Census. (2009). Department of Agriculture: Economic Planning and Statistics Division. Suva,Fiji.

[7] Galvin, J. F. P., \& Jones, C. D. (2009). The weather and climate of the tropics: Part 10-Tropical agriculture. Weather, 64(6), 156-161Winter, D. F., \& Dick, W. K. (1984). A method for compensating neutral-to-earth potentials in dairy facilities. In National Conference on Agricultural Electronics Applications, Hyatt Regency Illinois Center, Chicago, Ill.(USA), 11-13 Dec 1983. American Society of Agricultural Engineers.

[8] Dornan, M. (2015). Renewable energy development in small island developing states of the pacific. Resources, 4(3), 491-496.

[9] Comparative Report - Pacific Region Electricity Bills. (2016). Utilities Regulatory Authority of Vanuatu. Retrieved from http://www.ura.gov.vu/attachments/article/106/Comparative\%20Report\%20\%20Pacific\%20Region\%20Electricity\%20Bills\%20June\%202016\%20(2).pdf

[10] Climate and Disaster Resilience. (2016) (p. 70). Pacific Possible - The World Bank Group. Retrieved from: http://pubdocs.worldbank.org/en/720371469614841726/PACIFIC-POSSIBLE-Climate.pdf

[11] Robert, S., Matte, J. J., Bertin-Mahieux, J., \& Martineau, G. P. (1991). Effects of continuous stray voltage on health, growth and welfare of fattening pigs. Canadian Journal of Veterinary Research, 55(4), 371.

[12] Zhou, Q. Y., Shimada, J., \& Sato, A. (2001). Three-dimensional spatial and temporal monitoring of soil water content using electrical resistivity tomography. Water Resources Research, 37(2), 273-285.

[13] The Climate of Fiji. (2013). Information Sheet No. 35. Fiji Meteorological Service. Retrieved from http://www.met.gov.fj/ClimateofFiji.pdf

[14] Wiles, J. C. (2012). Photovoltaic system grounding. Southwest Technology Development Institute College of Engineering New Mexico State University October.

[15] F. R.. Islam,\& Pota, H. R. (2011). Design a PV-AF system using V2G technology to improve power quality. In IECON 2011-37th Annual Conference of the IEEE Industrial Electronics Society (pp. 861-866).

[16] F. R. Islam,, \& Pota, H. R. (2012). Impact of Dynamic PHEV Load On Photovoltaic System. International Journal of Electrical \& Computer Engineering (2088-8708), 2(5).

[17] British Standard, B. S. 7430: 1998. Code of Practice for Earthing

[18] Cabareda, L. (2011, November). Natural Lonizing System of Electrical Protection against Atmospheric Discharges (Lightning). In World Renewable Energy Congress-Sweden; 8-13 May; 2011; Linköping; Sweden (No. 057, 31293136). Linköping University Electronic Press.

[19] IEEE Industry Applications Society. Power System Technologies Committee. (1982). IEEE recommended practice for grounding of industrial and commercial power systems (Vol. 142). IEEE.

[20] Xu, W., Acharya, J. R., Torquato, R., \& Yong, J. (2015). A method to determine stray voltage sources-Part I: Concept and theory. IEEE Transactions on Power Delivery, 30(2), 713-719.

[21] Reinemann, D. J. (2012). Stray voltage and milk quality: a review. Veterinary Clinics: Food Animal Practice, 28(2), 321-345.

[22] Breuer, K., Hemsworth, P. H., Barnett, J. L., Matthews, L. R., \& Coleman, G. J. (2000). Behavioural response to humans and the productivity of commercial dairy cows. Applied Animal Behaviour Science, 66(4), 273-288

[23] FAOSTAT. (2018). Retrieved June 5, 2018, from http://www.fao.org/faostat/en/\#data/ql

[24] Koroi, R. (2017). FBC News - Dairy farmers call for increase in milk prices. Retrieved June 5, 2018, from http://www.fbc.com.fj/fiji/47122/dairy-farmers-call-for-increase-in-milk-prices

[25] Visscher, A. W. (n.d.). Stray voltage. Calgary: Alberta Dairy Management. Retrieved from http://www.agromedia.ca/ADM_Articles/content/strayvol.pdf

[26] Pacific Gas and Electric Company (2007). Stray voltage. (2007). Power Quality Bulletin, (2), 1-3. Retrieved from: https://www.pge.com/includes/docs/pdfs/about/news/outagestatus/powerquality/power_quality_bulletinissue_no.2_stray_volt.pdf

[27] Winter, D. F., \& Dick, W. K. (1984). A method for compensating neutral-to-earth potentials in dairy facilities. In National Conference on Agricultural Electronics Applications, Hyatt Regency Illinois Center, Chicago, Ill. (USA), 11-13 Dec 1983. American Society of Agricultural Engineers.

[28] Sass, L., \& Thompson, J. (1993). Stray Voltage: Is It Really a Problem? Iowa State University Veterinarian, 55(1), 6.

[29] Yelkovac, P. G. (1994). Homogenizing the Law of Stray Voltage : An Electrifying Attempt to Corral the Controversy, Val. U. L. Rev. 28(3), 1111-1159. 